\title{
Effects of non-lint material on heritability estimates of cotton fiber length parameters
}

\author{
João Paulo S. Morais • Brendan R. Kelly • Abu Sayeed • Eric F. Hequet
}

Received: 23 October 2019/Accepted: 26 November 2019/Published online: 21 January 2020

(C) The Author(s) 2020

\begin{abstract}
Fiber length is an important parameter to spin cotton fibers. Cotton breeders work to improve length, and research samples may be machine-harvested, resulting in variability for trash content between samples within the same experiment. There is evidence that trash may directly or indirectly affect the measurement of some fiber quality parameters like micronaire and strength. We hypothesize that the presence of trash particles in the samples may compromise the quality of the length measurement and screening decisions in breeding programs. In order to test this hypothesis, we developed an experiment to evaluate the heritability of length parameters for entries with the same genetic background and affected by the same environment with different trash content. The heritability estimates for
\end{abstract}

J. P. S. Morais $(\bowtie) \cdot$ B. R. Kelly · A. Sayeed .

E. F. Hequet

Plant and Soil Sciences Department, Texas Tech

University, Lubbock, TX 79409, USA

e-mail: joao.morais@embrapa.br

B. R. Kelly

e-mail: brendan.kelly@ttu.edu

E. F. Hequet

e-mail: eric.hequet@ttu.edu

J. P. S. Morais

Embrapa Algodão, Campina Grande, PB 58428, Brazil

B. R. Kelly

Texas A\&M AgriLife Research \& Extension Center at Lubbock, Lubbock, TX 79403, USA samples with high trash content are different from the estimates for samples with native low trash content. Cleaning trashy samples with a laboratory-scale lint cleaner brings the heritability estimates closer to the calculated values for samples with native low trash content. Although the values are similar, the types of variation are not the same. These results indicate that breeders must avoid making decisions based on samples with high trash content. Breeders should base their decisions on samples with low original trash content because this type of sample provides research results closer to the native length distribution.

Keywords North Carolina design II - Fiber quality · Trash $\cdot$ Processing $\cdot$ Lint cleaning $\cdot$ Breeding

\section{Introduction}

Cotton fiber yield and quality are both essential elements for the producers while fiber quality is of the utmost importance to market the crop and transform it into a textile product. Farmers need varieties with high yield while spinning mills need cotton with a fiber quality profile that allows them to spin a yarn of a given quality. This demand leads cotton breeders to target the improvement of both fiber yield and quality (Ethridge and Hudson 1998; Stewart et al. 2010).

Fiber quality is a complex trait. There are many interrelated fiber quality parameters critical to the 
spinning industry. This myriad of parameters and their interrelationships cannot be summarized as a single variable. Different spinning technologies and end products will need fibers with a different set of quality properties. For example, fiber length is essential for ring spinning, but the fibers must also be strong and mature, or they will break during processing (Elhawary 2014; Kelly and Hequet 2018).

Cotton breeders usually work with seed cotton harvested by hand from individual plants or harvested by research-type machines (e.g., stripper harvesters without field cleaners) from rows to make their selections while cotton producers harvest with commercialtype machines (e.g., cotton stripers with field cleaners). These differences in harvesting methods can result in differences in non-lint content; such as pieces of leaves, bracts, and stem (Faulkner et al. 2011a,b). Additionally, the type of non-lint material can vary from one sample to the next (van der Sluijs and Hunter 2017). The non-lint content is generally referred to as trash.

Trash content has the potential to cause problems with fiber quality measurements (Peirce and Lord 1939; Liu and Delhom 2018). For example, the micronaire, a combination of maturity and fineness, is based on the measurement of airflow through a plug of lint of a known weight in a chamber of known dimension (Lord 1955, 1956). Excessive trash content in the sample may create air channels through the plug of fibers, resulting in an unreliable micronaire reading. Furthermore, since the mass of trash in the sample is unknown, the true lint mass is unknown (Lord 1956; Fryer et al. 1996).

Excessive sample trash may cause problems with other High Volume Instrument (HVI) measurements as well. For example, the micronaire reading is used in combination with the optical amount of the fiber beard being broken to estimate the sample mass during bundle strength measurement. An imperfect micronaire measurement will affect the estimate of the beard mass and, therefore, the strength measurement (Keskin et al. 2001; Naylor et al. 2014). Thus, trash can affect the reliability of HVI measurements directly and indirectly.

Fiber length is often the focus of trait improvement efforts in cotton because it is a critical fiber quality property in spinning, and it is heritable (Elhawary 2014; Campbell et al. 2018). The HVI measures fiber length using the fibrogram principle (Delhom et al. 2018). In the fibrogram principle, a sample is deposited into a fibrosampler and pressed against a perforated curved wall, forcing tufts of fibers to protrude through openings (Fig. 1a, b). A metallic comb passes over the external surface of the fibrosampler, allowing fibers to be randomly captured by the comb teeth, forming a fiber beard (Fig. 1c). The beard is brushed against the opposed surface of the fibrosampler, on a carding surface that removes most of the fibers that are not caught in the comb and begins to parallelize the beard (Fig. 1d). Finally, a brush straightens and removes loose fibers from the beard before exposing the fibers to a light scanner that generates a fibrogram. In the fibrograph method, the attenuation of light is measured over the randomly caught beard of fibers, producing a curve representing the optical amount versus displacement. The optical amount is assumed to be proportional to the weight of the fiber beard at each point. If this assumption is true, the fibrogram would correspond to a fiber length distribution by weight. The HVI reports the upper half mean length (UHML) and the uniformity index (UI), a percentage ratio between mean length (ML) and UHML (Chu and Riley 1997; ASTM 2013; Delhom et al. 2018). However, this method was developed on clean samples and the effects of trash on this method are not well-documented (Hertel and Zervigon 1936; Hertel 1940).

While the HVI is the dominant marketing tool for cotton classification, the Advanced Fiber Information System (AFIS) is commonly used in spinning mills and research applications. The AFIS measures properties of individual fibers and creates by-number distributions related to fiber quality attributes, such as length (Shofner et al. 1995). Researchers typically compare treatments based on parameters extracted from these distributions; such as short fiber content by number (SFCn) (the percentage of fibers with a length equal or smaller than $12.5 \mathrm{~mm}$ ), the mean fiber length by number ( $\mathrm{Ln})$, and the $5 \%$ longer fibers by number (L5\%) (Kelly et al. 2013; Kelly and Hequet 2018). The AFIS also generates fiber distributions by-weight. Several parameters can be derived from these distributions; such as the mean fiber length by weight (Lw) and the upper quartile length by weight (UQLw). However, the by-weight measurements are calculated from the length by-number distribution assuming a constant fiber linear density across length groups (Krifa 2006; Delhom et al. 2018).

The AFIS fiber quality parameters are based on different fiber quality measurement principles than 


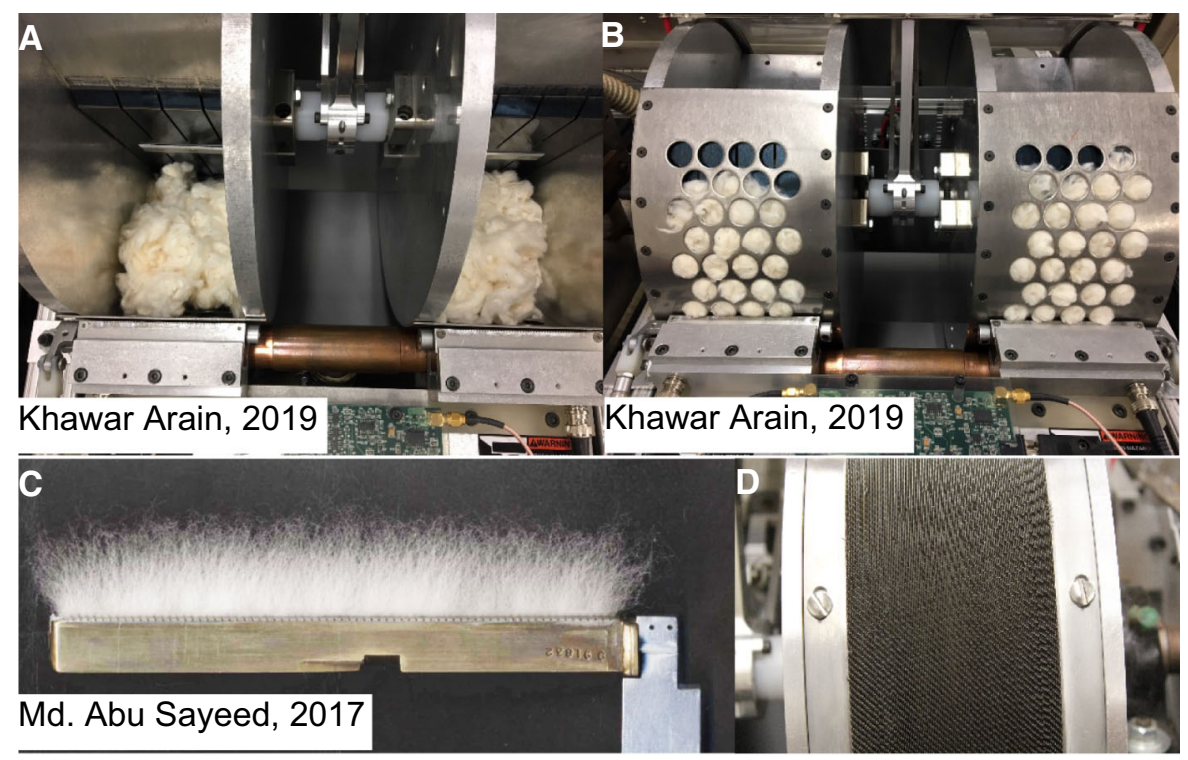

Fig. 1 Fibrosampler in the high volume instrument (HVI). A cotton sample is deposited into the fibrosampler basket (a). Fibers protrude from the perforated curved wall (b). The comb is

HVI. Samples are presented to the AFIS fiber individualizer as a hand-shaped sliver. The sliver is submitted to the action of a perforated pinned cylinder that individualizes fibers and removes trash particles. An airflow separates trash and fibers, carrying them to two different sensors. The optical sensors will then measure fibers, fiber entanglements, i.e., neps, and trash particles. Not all fibers that are presented to the sensor are used to create the reported fiber length distribution. There are electronic filters that reject the result from some of the fibers if the fiber has, for example, a calculated speed faster than the airflow or a signal that cannot be fully distinguished from a nep signal (Shofner 1985; Shofner et al. 1995; Shofner and Shofner 1999; Kelly et al. 2013).

The two systems, HVI and AFIS, can provide fiber length distributions but they are not equivalent. Cottonseed has a native fiber length distribution. During ginning, some fibers may be broken or removed from the sample. If the lint is then processed with a lint cleaner, more breakage and removal may happen, increasing the difference between the native fiber length distribution and the post-processing distribution (Bel et al. 1991). The HVI fibrogram is a tool to measure and report the native fiber distribution modified by processing at the gin. The AFIS has a built-in cleaning device that may also break fibers passed externally on this surface, creating the fiber beard (c). The comb is brushed on a carding surface on the fibrosampler (d) to remove free fibers and to begin to parallelize the beard

(Shofner and Shofner 1999). Therefore, results from the AFIS report on the native length distribution modified by the effect of processing at the gin and the effect of AFIS processing. In addition, the HVI cannot measure the very short fibers as it begins to scan the beard at $3.81 \mathrm{~mm}$ from the comb.

Finally, trash particles may be present in the sample while the beard is formed prior to the HVI length measurement or in the AFIS sliver. We hypothesize that the presence of trash particles in the samples may compromise the quality of the length measurement and screening decisions in breeding programs. Thus, breeders may need to manage the trash content in their samples. However, it is often not practical to apply industrial-scale processes to research material. Therefore, we devised an experiment to evaluate three trash management strategies and the effects that these strategies have on fiber quality length heritability estimates.

\section{Material and methods}

Mating design and plant materials

A North Carolina mating design II (NCII) was chosen to perform this experiment. This mating design was 
selected because it provides the information needed to meet our objective without requiring as many resources as a full diallel (Fristche-Neto et al. 2018). The heritability estimates used in this research were calculated based on the parental lines and the $F_{2}$ generation. (Comstock and Robinson 1952; Tang et al. 1996; Hill et al. 1998).

\section{Identifying parental material}

A set of six cultivars were chosen for this experiment based on a range of upper half mean lengths (UHML) as measured by HVI. The selected cultivars were split into maternal and paternal sets of three varieties each. Each parental set is composed of cultivars representing low, medium, and high UHML (Boman et al. 2010; Kelley and Keys 2015).

\section{Obtaining $\mathrm{F}_{2}$ seed}

The parental seeds were planted $2.54 \mathrm{~cm}$ deep in perforated plastic pots of $30 \mathrm{~L}$ with $25 \mathrm{~L}$ of Sungro Metro-Mix ${ }^{\circledR} 360$ at the Texas Tech University greenhouse. Each pot was fertilized with $32 \mathrm{~g}$ of Osmocote ${ }^{\circledR}$ Classic Fertilizer 14-14-14 and received $0.5 \mathrm{~g}$ of Mantra ${ }^{\circledR} 1 \mathrm{G}$. Four seeds were planted per pot and thinned to two seedlings after 3 weeks. Each pot was weekly watered as needed until water began to drop from the bottom. Plants were sprayed with a rotation of insecticides to minimize acquired resistance. The used insecticides were Avid ${ }^{\circledR}$ 0.15EC, Distance ${ }^{\circledR}$, Discuss ${ }^{\circledR}$, and Pylon ${ }^{\circledR}$. Closed flowers from the maternal set of plants were emasculated in the afternoon of the day before anthesis. Stigma and style were sprayed with tap water and covered with a piece of paper straw to protect them and avoid undesired outcrossing. In the morning of anthesis, the piece of paper straw was removed. Open flowers from the paternal set were picked and their pollen was sprinkled on the stigma of emasculated flowers. After crossing, the pollinated flowers were covered again with the piece of paper straw.

Seedcotton was hand-picked from each boll in order to obtain $F_{1}$ seed. The seed cotton was ginned with a laboratory-scale roller gin (Dennis Manufacturer, Athens, TX), delinted with a research mechanical delinter at Texas A\&M AgriLife Research \& Extension Center, Lubbock TX, and planted by hand at the Texas Tech University research farm in
Lubbock, Texas, on a loam soil with drip irrigation and following the recommendation for irrigated cotton production in the region (Ayele et al. 2018). A total of $75 \mathrm{~F}_{1}$ seeds for each of the nine crosses were planted in unreplicated 7.6-m long plots. Three seeds were planted per hill and the hills were spaced $30 \mathrm{~cm}$ apart. Seedlings were thinned to one plant per hill after 3 weeks. The hybrid plants were self-pollinated using clips to prevent flower opening. Seedcotton was handpicked from each boll in order to obtain $\mathrm{F}_{2}$ seeds. The seedcotton was ginned with a laboratory-scale roller gin (Dennis Manufacturer, Athens, TX), delinted with sulfuric acid $20 \% \mathrm{w} / \mathrm{w}$ in a delinting system at Texas Tech University, and prepared for machine planting.

Field experiment

The heritability experiment was planted at the Texas Tech University Research farm, Lubbock, Texas, in a completely randomized block design with three field replications. Each plot was a single row 6.1-m long with a density of 10 seeds per meter to simulate commercial planting (Fig. 2). The seeds were planted on a loam soil with drip irrigation and following the recommendation for irrigated cotton production in the region (Ayele et al. 2018). During the experiment, the accumulated rainfall was $272 \mathrm{~mm}$ and growing degree days $\left(\mathrm{GDD}_{15.6}\right)$ were 1308 units (Snowden et al. 2013).

\section{Harvesting, ginning, and processing}

A 50-boll-sample was hand-picked from each $\mathrm{F}_{2}$ plot from all boll positions to obtain samples that are about identical to typical breeding samples, i.e., very low trash content due to hand harvesting. The remaining seed cotton from each plot was mechanically harvested with a cotton stripper with no field cleaner to obtain samples with a higher amount of non-lint content. The mechanically harvested samples were pre-cleaned with a burr and stick extractor in an Imperial III Lummus gin to remove sticks and other large pieces of foreign material that could impede laboratory-scale ginning. The two types of samples were conditioned at $21 \pm 1{ }^{\circ} \mathrm{C}$ and relative humidity of $55 \pm 5 \%$ for 7 days before ginning with a laboratory-scale Compass 10-saw gin (Model MG1010), with no seed cotton cleaner and no lint cleaner.

Subsamples of lint from the trashy samples were mechanically processed with a Shirley analyzer 


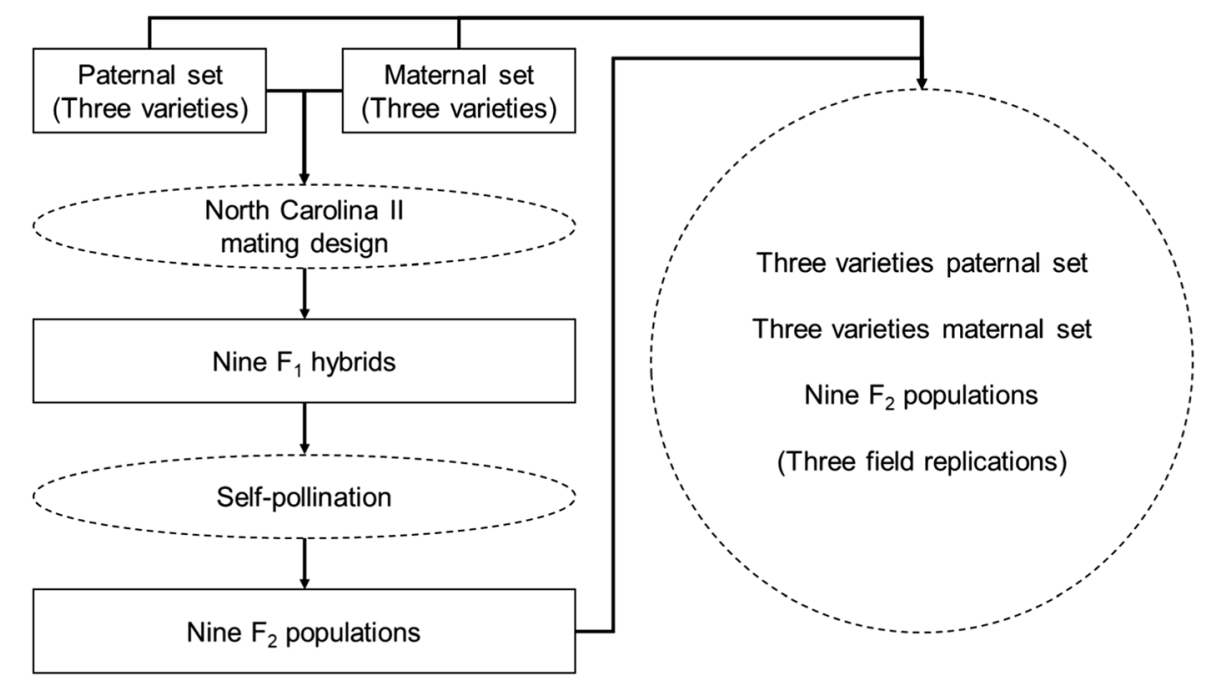

Fig. 2 Flowchart from original crosses to field experiment

laboratory-scale lint cleaner. This device was chosen because it mimics the cleaning action and mechanical stress that is applied during industrial processing of cotton (Pfeiffenberger 1944). These samples represent a scenario where trash particles are not managed in the field but instead removed in the laboratory prior to fiber quality testing.

Fiber quality testing

The three different types of lint samples were conditioned at $21 \pm 1{ }^{\circ} \mathrm{C}$ and $65 \pm 2 \%$ of relative humidity (ASTM 2016) and tested by HVI following a 4-4-10 protocol, which consists of four measurements of micronaire, four measurements of trash/color, and ten measurements of length/strength/elongation. The samples were also tested by the Advanced Fiber Information System (AFIS) following a protocol of five replications of 3000 fibers (Fig. 3).

\section{Heritability estimates and statistics}

Mean values for fiber quality parameters (leaf grade, visible foreign matter, trash count, dust count, nep count, HVI upper half mean length, HVI mean length, AFIS short fiber content by number, AFIS mean length by number, AFIS upper quartile length by weight, and AFIS 5\% longer fibers by number) in the $F_{2}$ populations were analyzed using analysis of variance
(ANOVA) and honest significant difference (HSD) Tukey's test at $5 \%$ of significance.

Heritability estimates for fiber quality parameters were performed based on the variance components obtained from the half-sibling experimental design (Comstock and Robinson 1948; Hill et al. 1998). The NCII can be analyzed as a two-way ANOVA factorial design in which one factor is the maternal component while the other factor is the paternal component. Following this procedure, the parental components are related to the additive variance component of heritability $\left(\mathrm{V}_{\mathrm{a}}\right)$, the interaction between the components is related to the non-additive variance component of heritability $\left(\mathrm{V}_{\mathrm{d}}\right)$, and the error is related to environmental variance $\left(\mathrm{V}_{\mathrm{e}}\right)$ (Table 1$)$.

The broad sense heritability estimate was calculated as the fraction of all components of genetic variance over the total variance: $\mathrm{H}^{2}=\left(\mathrm{V}_{\mathrm{a} 1}+\mathrm{V}_{\mathrm{a} 2 \text { - }}\right.$ $\left.+V_{d}\right) /\left(V_{a 1}+V_{a 2}+V_{d}+V_{e}\right)$. The narrow sense heritability estimate was calculate as the fraction of the additive variance component and the total variance: $\quad \mathrm{h} 2=\left(\mathrm{V}_{\mathrm{a} 1}+\mathrm{V}_{\mathrm{a} 2}\right) /\left(\mathrm{V}_{\mathrm{a} 1}+\mathrm{V}_{\mathrm{a} 2}+\mathrm{V}_{\mathrm{d}}+\mathrm{V}_{\mathrm{e}}\right)$. Broad sense $\left(\mathrm{H}^{2}\right)$ and narrow sense heritability $\left(\mathrm{h}^{2}\right)$ estimates were calculated for parameters obtained from HVI and AFIS. 


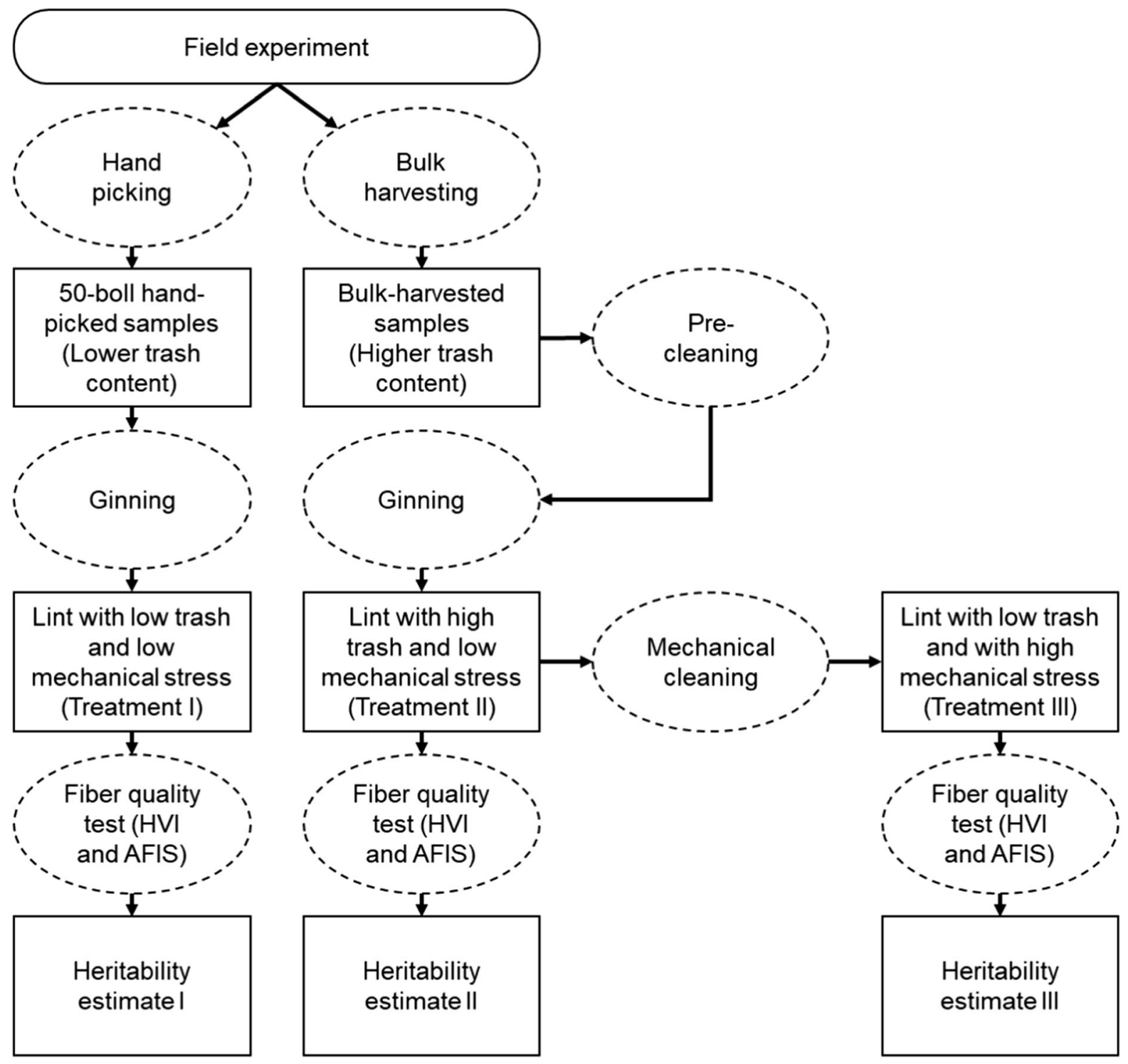

Fig. 3 Flowchart from the field experiment to fiber quality analysis

Table 1 Two-way analysis of variance used to calculate the heritability estimates in this research

\begin{tabular}{lcc}
\hline Item of variance & Degrees of freedom & Component of variance \\
\hline Males & 2 & $\mathrm{~V}_{\mathrm{a} 1}$ \\
Females & 2 & $\mathrm{~V}_{\mathrm{a} 2}$ \\
Males $\times$ females & 4 & $\mathrm{~V}_{\mathrm{d}}$ \\
Within plots & 18 & $\mathrm{~V}_{\mathrm{e}}$ \\
Total & 26 & $\mathrm{~V}_{\mathrm{p}}$ \\
\hline
\end{tabular}




\section{Results and discussions}

\section{Sample type characteristics}

A total of three types of samples with different trash contents were obtained from each plot following this protocol; low trash content with low mechanical processing (treatment I), high trash content with low mechanical processing (treatment II), and low trash content with high mechanical processing (treatment III). The HVI measurement of trash is based on image analysis of the sample surface and is reported on an ordinal scale from 1 to 8 (Cotton Incorporated 2013). The treatment I samples have an average HVI leaf grade of 1.1, while the treatment II has an intermediate value of 4.3. Cleaning treatment II samples resulted in treatment III samples, with an average leaf grade of 1.0, comparable to the treatment I samples (Table 2).

The AFIS provides a different method for measuring the trash content. It is based on the aeromechanical separation of trash particles from the lint (Shofner and Shofner 1999). The trend observed with HVI holds true with the AFIS assessment of visible foreign matter (VFM), trash, and dust for the three types of samples. The samples with lower leaf grade, treatments I and III, have the lowest levels of non-lint content according to AFIS.

Fiber entanglements, called neps, can create imperfections in spun yarns (van der Sluijs and Hunter 2016). The highest level of neps/g in this experiment was obtained with the laboratory cleaned samples. The mechanical processing used to clean the samples also has the potential to reduce fiber quality by breaking and entangling fibers, increasing the measured number of neps.
Parental material characteristics

The parents were selected based on reported data for their HVI upper half mean length (UHML) to create a large range for length. The HVI data for the hand picked parents show a range of $3.04 \mathrm{~mm}$ for UHML and ML, and $1.87 \%$ for UI (Table 3). Compared to the global average, these values have a range of $-4.54 \%$ to $6.50 \%$ for UHML, $-5.45 \%$ to $7.92 \%$ for the mean length (ML), and -0.94 to $1.32 \%$ for UI. UI is the ratio of ML to UHML (ASTM 2013). The observed range of variability for UI is narrower than the observed range for UHML and ML. Without a large range for a property, the experimental variability is low and the heritability measurements are negatively impacted. Therefore, we calculated heritability estimates only for UHML and ML.

The AFIS data exhibit a range of $-4.70 \%$ to $8.06 \%$ for the $5 \%$ longer fibers (L5\%), $-4.52 \%$ to $7.83 \%$ for the mean length by number $(\operatorname{Ln}),-13.76 \%$ to $14.28 \%$ for short fiber content by number (SFCn), and $-4.22 \%$ to $7.30 \%$ for the upper quartile length by number (UQLw) (Table 3). The observed ranges for AFIS length parameters are as good as the ranges observed for HVI UHML and ML, and they were used in our analyses.

Heritability estimates for HVI length measurements

The UHML and ML have the highest broad and narrow sense heritability estimates when measured on hand-picked samples, with low trash content and low mechanical processing. The lowest heritability estimates were obtained on bulk harvested samples, with

Table 2 Average value for parameters related to trash and processing in nine $F_{2}$ samples, with three field replications, from three treatments with different levels of trash content and mechanical processing

\begin{tabular}{lllclc}
\hline Treatment* & Leaf (no unit) & VFM $^{* *}(\%)$ & Trash/g (count) & Dust/g (count) & Neps/g (count) \\
\hline Treatment I & $1.1 \pm 0.1^{\mathrm{a}}$ & $0.30 \pm 0.03^{\mathrm{a}}$ & $12 \pm 2^{\mathrm{a}}$ & $64 \pm 7^{\mathrm{a}}$ & $106 \pm 3^{\mathrm{a}}$ \\
Treatment II & $4.3 \pm 0.2^{\mathrm{b}}$ & $2.20 \pm 0.14^{\mathrm{b}}$ & $132 \pm 9^{\mathrm{b}}$ & $420 \pm 27^{\mathrm{b}}$ & $155 \pm 3^{\mathrm{b}}$ \\
Treatment III & $1.0 \pm 0.1^{\mathrm{a}}$ & $0.20 \pm 0.03^{\mathrm{a}}$ & $13 \pm 1^{\mathrm{a}}$ & $54 \pm 5^{\mathrm{a}}$ & $180 \pm 4^{\mathrm{c}}$ \\
\hline
\end{tabular}

*Average value for three field replications \pm SE. Means in the column followed by the same letter are not statistically different by HSD Tukey's test at $5 \%$ of significance. Treatment I: samples with low trash content and low mechanical stress; treatment II: samples with high trash content and low mechanical stress; treatment III: samples with low trash content and high mechanical stress

**Visible foreign matter 
Table 3 Fiber quality properties of the hand picked parental varieties with three field replications tested by HVI and AFIS

\begin{tabular}{|c|c|c|c|c|c|c|c|c|}
\hline $\begin{array}{l}\text { HVI } \\
\text { Parameter* }\end{array}$ & \multicolumn{2}{|c|}{$\begin{array}{l}\text { Upper half mean length } \\
(\mathrm{mm})\end{array}$} & $\begin{array}{l}\text { Mean length } \\
(\mathrm{mm})\end{array}$ & $\begin{array}{l}\text { Uniformity index } \\
(\%)\end{array}$ & $\begin{array}{l}\text { Micronaire (no } \\
\text { unit) }\end{array}$ & \multicolumn{2}{|c|}{$\begin{array}{l}\text { Strength } \\
\left(\mathrm{kN} \cdot \mathrm{m} \cdot \mathrm{kg}^{-1}\right)\end{array}$} & $\begin{array}{l}\text { Elongation } \\
(\%)\end{array}$ \\
\hline \multicolumn{9}{|l|}{ Maternal set } \\
\hline Cultivar A & \multicolumn{2}{|l|}{$26.25 \pm 0.29$} & $21.50 \pm 0.25$ & $81.90 \pm 0.12$ & $4.90 \pm 0.08$ & \multicolumn{2}{|c|}{$273.0 \pm 4.9$} & $7.03 \pm 0.12$ \\
\hline Cultivar B & \multicolumn{2}{|l|}{$26.59 \pm 0.39$} & $22.08 \pm 0.42$ & $83.03 \pm 0.24$ & $5.24 \pm 0.10$ & \multicolumn{2}{|c|}{$291.4 \pm 1.7$} & $7.27 \pm 0.03$ \\
\hline Cultivar C & \multicolumn{2}{|l|}{$29.29 \pm 0.78$} & $24.54 \pm 0.92$ & $83.77 \pm 0.55$ & $4.57 \pm 0.03$ & \multicolumn{2}{|c|}{$307.3 \pm 4.9$} & $5.97 \pm 0.09$ \\
\hline \multicolumn{9}{|l|}{ Paternal set } \\
\hline Cultivar X & \multicolumn{2}{|l|}{$27.43 \pm 0.44$} & $22.72 \pm 0.51$ & $82.80 \pm 0.32$ & $4.93 \pm 0.05$ & \multicolumn{2}{|c|}{$287.7 \pm 1.9$} & $8.10 \pm 0.06$ \\
\hline Cultivar Y & \multicolumn{2}{|l|}{$28.19 \pm 0.51$} & $23.12 \pm 0.58$ & $82.00 \pm 0.40$ & $4.84 \pm 0.03$ & \multicolumn{2}{|c|}{$274.0 \pm 1.7$} & $5.77 \pm 0.07$ \\
\hline Cultivar Z & \multicolumn{2}{|l|}{$27.26 \pm 0.64$} & $22.51 \pm 0.54$ & $82.57 \pm 0.13$ & $4.87 \pm 0.05$ & \multicolumn{2}{|c|}{$304.1 \pm 6.4$} & $6.30 \pm 0.10$ \\
\hline $\begin{array}{l}\text { Global } \\
\text { average }\end{array}$ & \multicolumn{2}{|l|}{$27.50 \pm 0.27$} & $22.74 \pm 0.26$ & $82.68 \pm 0.19$ & $4.89 \pm 0.05$ & \multicolumn{2}{|c|}{$289.6 \pm 3.5$} & $6.74 \pm 0.20$ \\
\hline $\begin{array}{l}\text { AFIS } \\
\text { Parameter* }\end{array}$ & $\begin{array}{l}5 \% \text { longer fibers by } \\
\text { number }(\mathrm{mm})\end{array}$ & \multicolumn{2}{|c|}{$\begin{array}{l}\text { Mean length by } \\
\text { number }(\mathrm{mm})\end{array}$} & $\begin{array}{l}\text { Short fiber content } \\
\text { by number }(\%)\end{array}$ & \multicolumn{2}{|c|}{$\begin{array}{l}\text { Upper quartile length } \\
\text { by weight }(\mathrm{mm})\end{array}$} & $\begin{array}{l}\text { Fineness } \\
(\text { mtex })\end{array}$ & $\begin{array}{l}\text { Maturity ratio } \\
\text { (no unit) }\end{array}$ \\
\hline \multicolumn{9}{|l|}{ Maternal set } \\
\hline Cultivar A & $31.33 \pm 0.34$ & \multicolumn{2}{|c|}{$19.64 \pm 0.22$} & $21.2 \pm 0.8$ & $27.60 \pm 0.31$ & & $192 \pm 1$ & $0.92 \pm 0.02$ \\
\hline Cultivar B & $30.99 \pm 0.44$ & \multicolumn{2}{|c|}{$20.32 \pm 0.51$} & $17.7 \pm 1.6$ & $27.43 \pm 0.39$ & & $192 \pm 1$ & $0.96 \pm 0.02$ \\
\hline Cultivar C & $35.14 \pm 0.72$ & \multicolumn{2}{|c|}{$22.18 \pm 0.59$} & $16.3 \pm 0.9$ & $30.73 \pm 0.64$ & & $173 \pm 1$ & $0.96 \pm 0.02$ \\
\hline \multicolumn{9}{|l|}{ Paternal set } \\
\hline Cultivar X & $32.17 \pm 0.34$ & \multicolumn{2}{|c|}{$20.83 \pm 0.64$} & $17.3 \pm 2.0$ & $28.36 \pm 0.34$ & & $187 \pm 1$ & $0.92 \pm 0.02$ \\
\hline Cultivar Y & $33.70 \pm 0.47$ & \multicolumn{2}{|c|}{$20.40 \pm 0.37$} & $21.6 \pm 1.0$ & $29.72 \pm 0.51$ & & $180 \pm 1$ & $0.95 \pm 0.01$ \\
\hline Cultivar Z & $31.83 \pm 0.45$ & \multicolumn{2}{|c|}{$20.07 \pm 0.39$} & $19.5 \pm 1.5$ & $28.02 \pm 0.31$ & & $179 \pm 1$ & $0.95 \pm 0.02$ \\
\hline $\begin{array}{l}\text { Global } \\
\text { average }\end{array}$ & $32.52 \pm 0.39$ & \multicolumn{2}{|c|}{$20.57 \pm 0.25$} & $18.9 \pm 0.56$ & $28.64 \pm 0.32$ & & $174 \pm 2$ & $0.94 \pm 0.07$ \\
\hline
\end{tabular}

*HVI High volume instrument, average value for three field replications, four laboratory readings for micronaire, and 10 readings for other parameters \pm SE. AFIS Advanced fiber information system, average value for three field replications and five laboratory readings of 3000 fibers $\pm \mathrm{SE}$

high trash and low mechanical processing (Tables 1,2, 4).

The treatment I samples have a narrow sense heritability estimate of 0.622 , while treatment II samples have a value of 0.540 . Similarly, the heritability estimates of ML for treatment I samples are 0.579 and 0.478 for treatment II samples. The samples in both treatments have the same genetic background and were managed the same way in the same field. Therefore, the reduced estimated heritability is reflecting the effects of harvesting and cleaning methods.

The UHML and strength are traits with high heritability. Analyzing data from 13 experiments, Campbell et al. (2018) observed that the narrow sense heritability for UHML ranged from 0.00 to 0.70 , with an average value of 0.30 . This is an indication that the data used in this experiment are of good quality.
Seedcotton samples have a native length distribution. The treatment I samples have low trash content and low mechanical process, possibly resembling more the native length distribution. Therefore, the treatment I samples will serve as a reference point for the effects that trash and processing may have on other sample types.

There is a reduction in the heritability estimates for UHML and ML from the treatment I to treatment II. Trash may affect fiber sampling in the HVI, creating differences in the heritability estimates. As explained earlier, trash particles may result in fiber quality measurement bias. In the HVI, a comb takes fibers from the tufts of lint protruding through the orifices of the sampling basket, forming a fiber beard. Trash can interfere with this sampling mechanism and beard formation. Since trash is not uniformly distributed 
Table 4 Heritability estimates for HVI length fiber properties in three treatments of nine $\mathrm{F}_{2}$ samples, with three field replications, with different levels of trash content and mechanical processing

\begin{tabular}{lll}
\hline Parameter & $\begin{array}{l}\text { Upper half mean } \\
\text { length }(\mathrm{mm})\end{array}$ & $\begin{array}{l}\text { Mean length } \\
(\mathrm{mm})\end{array}$ \\
\hline
\end{tabular}

\section{HVI values}

Treatment*

$\begin{array}{lll}\text { Treatment I } & 27.9 \pm 0.2^{\mathrm{a}} & 23.2 \pm 0.2^{\mathrm{a}} \\ \text { Treatment II } & 27.9 \pm 0.2^{\mathrm{a}} & 23.0 \pm 0.2^{\mathrm{a}} \\ \text { Treatment III } & 27.5 \pm 0.2^{\mathrm{a}} & 22.4 \pm 0.1^{\mathrm{b}}\end{array}$

Broad sense heritability $\left(H^{2}\right)$

Treatment

$\begin{array}{lll}\text { Treatment I } & 0.701 & 0.650 \\ \text { Treatment II } & 0.564 & 0.513 \\ \text { Treatment III } & 0.625 & 0.538\end{array}$

Narrow sense heritability $\left(h^{2}\right)$

Treatment

$\begin{array}{lll}\text { Treatment I } & 0.622 & 0.579 \\ \text { Treatment II } & 0.540 & 0.478 \\ \text { Treatment III } & 0.588 & 0.538\end{array}$

*Average value for three field replications \pm SE. Means in the column followed by the same letter are not statistically different by HSD Tukey's test at 5\% of significance. Treatment I: samples with low trash content and low mechanical stress; treatment II: samples with high trash content and low mechanical stress; treatment III: samples with low trash content and high mechanical stress

within the sample, the population of fibers from one beard to another may be different for the same sample. The inflated within-sample variation imparted by this the environmental variation leads to reduced calculated heritability for treatment II samples.

The heritability estimates are based on the genetic component of the trait of interest, the variability imparted by environment, and the interaction between them. Among treatments, there is no significant difference for the heritability estimates for UHML and ML.

Nevertheless, we observed numerical differences among treatments for all analyzed fiber properties with the boll samples providing the highest estimates and the machine harvested samples the lowest. This confirms our hypothesis that trash content may negatively impact cotton fiber length measurements.

Researchers may not always measure fiber properties on samples with native low trash content. One alternative to managing trash is to clean samples in the laboratory before fiber quality assessment. It results in samples with low trash content and high mechanical stress, the treatment III samples. Treatment I and III samples have the same leaf grade, dust, and trash content (Tables 2, 4).

Cleaning samples with a Shirley analyzer, treatment III, resulted in heritability estimates for UHML and ML with values between the calculated values for treatments I and III (Table 4). The Shirley analyzer is a device created to simulate the lickerin of a card. In a lickerin, mechanical stress is applied to remove nonlint content from the samples (Pfeiffenberger 1944; ASTM 2012). This mechanism can break fibers, modify the native fiber length distribution, and entangle fibers creating neps. Cleaning samples with a Shirley analyzer removes the trash effect but adds a processing effect. There is no statistical difference at 95\% of confidence for the UHML between treatment I UHML $(27.9 \pm 0.4 \mathrm{~mm})$ and treatment III UHML $(27.5 \pm 0.3 \mathrm{~mm})$. Nevertheless, there is a statistical difference at $95 \%$ of confidence between treatment I ML $(23.2 \pm 0.4 \mathrm{~mm})$ and treatment III ML $(22.4 \pm 0.3 \mathrm{~mm})$.

The shortening of ML is evidence for processing effect. The heritability estimate numerically improved from treatment II to treatment III. We hypothesize that the improvement happens because fewer trash particles in the lint samples result in smaller within-sample variation among HVI combs.

\section{AFIS fiber quality properties}

\section{AFIS length distributions}

The AFIS provides length distributions by number. There are differences in the length distributions among the three treatments that will likely impact the means and heritability estimates for the AFIS length parameters (Fig. 4). As previously discussed, differences are related to the effects of harvesting and cleaning methods. The effects will impact the trash content and processing effect in the samples.

\section{The 5\% longer fibers by number and upper quartile length by weight}

The treatment I samples exhibit the highest numeric value of broad (0.691) and narrow sense (0.607) 

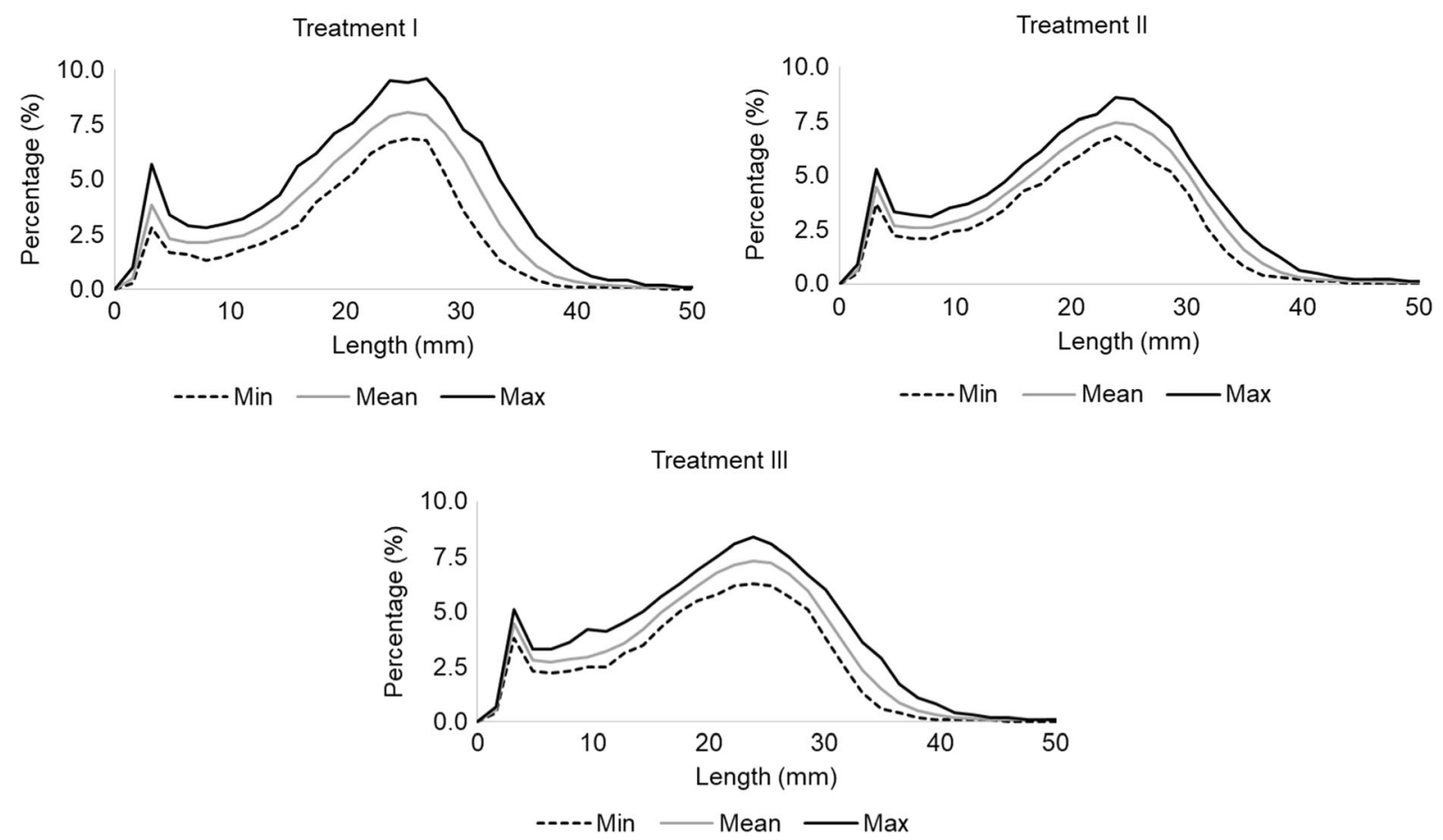

Fig. 4 AFIS length distributions for the analyzed samples. The black lines represent the range among the different bins and the grey line represents the average. Treatment I: samples with low

heritability estimates for the 5\% longer fiber by number (L5\%) while treatment II samples have a lower numerical value of broad (0.574) and narrow sense (0.572) heritability estimates for the L5\%, and treatment III samples have the lowest numerical value of broad (0.542) and narrow sense (0.517) heritability estimates for the L5\%. There are no statistical differences among the L5\% mean values for the three treatments. Although the average measurements for L5\% are not affected by trash or processing, the heritability measurements, based on variance, are impacted by trash and processing (Table 5).

The AFIS has a built-in fiber individualizer that is also a cleaning device. This perforated pinned cylinder applies mechanical processing on the tufts of fibers, separating trash and individual fibers. We hypothesize that some long fibers may entangle with trash in treatment II samples. When the fibers are individualized, a fraction of the long fibers entangled with trash may break or get removed with the trash or be rejected when presented to the length sensor. If degradation occurs on the length of the population of fibers related to the longer fibers, the heritability may be reduced. trash content and low mechanical stress; treatment II: samples with high trash content and low mechanical stress; treatment III: samples with low trash content and high mechanical stress

Treatment III samples were cleaned with a Shirley analyzer and this processing impacts the heritability measurements. Cleaning samples removes trash and adds processing effect. The longer fibers may be expelled together with trash or broken into shorter fibers or separated from trash but fragilized during cleaning. Some of the fragilized fibers from treatment III samples may break when they are processed by the AFIS individualizer. We hypothesize that this additional degradation of the longer fibers used to calculate the L5\% for treatment III samples resulted in the calculation of a lower heritability measurement.

The upper quartile length by weight (UQLw) measures longer fibers in the samples, but shorter than the population of fibers used to calculated the L5\%. The AFIS does not measure the weight of individual fibers. The reported distribution by-weight is calculated based on the distribution by-number and an assumption of constant linear density to all measured fibers. We hypothesize that the UQLw is following a similar trend to $\mathrm{L} 5 \%$, and the factors influencing the heritability estimates for $\mathrm{L} 5 \%$ will also impact the UQLw measurement calculations. 
Table 5 Heritability estimates for AFIS length fiber properties in three treatments of nine $\mathrm{F}_{2}$ samples, with three field replications, with different levels of trash content and mechanical processing

\begin{tabular}{lllll}
\hline Parameter & $\begin{array}{l}5 \% \text { longer fibers } \\
\text { by number }(\mathrm{mm})\end{array}$ & $\begin{array}{l}\text { Upper quartile } \\
\text { length by weight } \\
(\mathrm{mm})\end{array}$ & $\begin{array}{l}\text { Mean length by } \\
\text { number (mm) }\end{array}$ & $\begin{array}{l}\text { Short fiber content } \\
\text { by number }(\%)\end{array}$ \\
\hline
\end{tabular}

\section{AFIS values}

Treatment*

\begin{tabular}{|c|c|c|c|c|}
\hline Treatment I & $33.2 \pm 0.3^{\mathrm{a}}$ & $29.1 \pm 0.2^{\mathrm{a}}$ & $21.0 \pm 0.2^{\mathrm{a}}$ & $18.53 \pm 0.51^{\mathrm{a}}$ \\
\hline Treatment II & $32.8 \pm 0.2^{\mathrm{a}}$ & $28.7 \pm 0.2^{\mathrm{a}}$ & $19.9 \pm 0.1^{\mathrm{b}}$ & $22.26 \pm 0.40^{\mathrm{b}}$ \\
\hline Treatment III & $32.6 \pm 0.2^{\mathrm{a}}$ & $28.5 \pm 0.2^{\mathrm{a}}$ & $19.6 \pm 0.1^{\mathrm{b}}$ & $23.07 \pm 0.38^{b}$ \\
\hline
\end{tabular}

Broad sense heritability $\left(H^{2}\right)$

Treatment

\begin{tabular}{lllll} 
Treatment I & 0.691 & 0.662 & 0.471 & 0.535 \\
Treatment II & 0.574 & 0.622 & 0.642 & 0.779 \\
Treatment III & 0.542 & 0.562 & 0.446 & 0.610 \\
Narrow sense heritability & $\left(h^{2}\right)$ & & & 0.413 \\
Treatment & & & 0.427 & 0.694 \\
Treatment I & 0.607 & 0.603 & 0.617 & 0.464 \\
Treatment II & 0.572 & 0.607 & 0.530 & \\
Treatment III & 0.517 & 0.540 & & \\
\hline
\end{tabular}

*Average value for three field replications \pm SE. Means in the column followed by the same letter are not statistically different by HSD Tukey's test at 5\% of significance. Treatment I: samples with low trash content and low mechanical stress; treatment II: samples with high trash content and low mechanical stress; treatment III: samples with low trash content and high mechanical stress

\section{Mean length by number}

Treatment I presented the highest average mean length by number $(\mathrm{Ln})(21.0 \mathrm{~mm})$ and the lowest numeric value for narrow sense estimate (0.427) (Table 5). Treatment II has an average mean length shorter than treatment I $(19.9 \mathrm{~mm})$ and the highest numerical value for broad (0.642) and narrow (0.617) sense heritability estimates. Our hypothesis to explain this trend is similar to what was discussed for the HVI UHML. Treatment I presents the highest variation around the Ln (Fig. 4). This variation is the closest as possible as it can be measured in the native length distribution. As previously discussed, trash particles may entangle with longer fibers. These trash particles are not uniformly distributed within the samples. We hypothesize that some of these longer fibers will break when processed by the AFIS individualizer. The breakage will not uniformly happen in the different samples because the trash particles are not uniformly distributed. The number of shorter fibers will increase and the number of longer fibers will decrease, reducing the within-sample variation around the region related to Ln (Fig. 4), inflating the heritability estimate calculated for treatment II samples to values above the reference value calculated for treatment I. If this holds true, even if the calculated narrow sense heritability estimate for treatment II is higher than the value for treatment $I$, this is a value artificially inflated.

Treatment III samples were cleaned to remove the trash. The numeric value for the $\mathrm{Ln}$ narrow sense heritability estimate increases to a value (0.530) between the calculated estimates for treatments I and II. We hypothesize that fiber breakage may have occurred during cleaning or some fibers were fragilized and broke at the AFIS fiber individualizer. The additional breakage increases the variability for shorter fibers, numerically increasing within-sample variation and decreasing the heritability estimates. Nevertheless, the variation added by processing is different from the variation observed in treatment I (Fig. 4 and Table 5).

\section{Short fiber content by number}

Treatment I samples present the lowest average short fiber content by number (SFCn) (18.53\%) and lowest 
broad (0.535) and narrow (0.413) sense heritability estimates. The SFCn value for treatment II samples $(22.26 \%)$ is statistically higher than the value for treatment I. Treatment II samples have the highest numerical value for broad (0.779) and narrow (0.694) sense heritability estimates for SFCn. As previously discussed, we hypothesize that breakage may occur during fiber individualization because of trash entanglement with fibers. The breakage increases the number of shorter fibers in the samples, reducing within-sample variation and artificially inflating the calculated heritability estimate for SFCn.

The broad (0.610) and narrow (0.464) sense heritability estimates for the treatment III samples are an intermediate numerical value between the calculated heritability estimates for treatments I and II. As previously hypothesized, fiber breakage and fragilization during cleaning may have added variation to the fiber length distribution. If fragilized fibers break during fiber individualization, the within-sample variation increases and the heritability measurement is reduced.

\section{Conclusions}

Cotton researchers may obtain samples with different trash contents because of crop management, harvest, and even post-harvest processing such as ginning. Variability in the trash content may be also influenced by traits such as the shape of leaves and bracts, and the pubescence of leaves and stems. We observed by this research that trash is a factor in fiber quality assessment that degrades the quality of HVI and AFIS length measurements.

Samples with high trash content (treatment II) presented the lowest calculated heritability estimates for HVI length parameters. We hypothesize that trash particles impact HVI length measurements by entangling with the fibers, creating variation among fiber beards. This variation created by trash particles artificially increases variation in fiber length, obfuscating the true fiber length measurements. Cleaning samples (treatment III) reduces the trash content and increases the calculated heritability estimates. Nevertheless, this is the heritability of the native length distribution and the processing effect. The most appropriate trash management to minimize impacts on the fiber length heritability estimates is using samples with native low trash content and low processing effect (treatment I). If breeders can only obtain samples with high trash content, they need to increase the selection pressure to overcome the lower heritability estimates or they need to clean their samples before testing. This strategy may result in higher costs because breeders may need to test a larger number of entries than they would have if they used clean samples.

The AFIS has a built-in cleaning device, the AFIS fiber individualizer, which removes trash and ensures that clean fibers are delivered to the sensor. This device may create different impacts on fiber quality analysis. We observed by the results of our research that AFIS testing is also impacted by trash and processing. We hypothesize that trash particles may entangle with longer fibers. These fibers may be broken during individualization or may be carried away with the trash or their signal may be rejected at the fiber sensor. The degraded fiber length distribution results in length heritability estimates with values different from samples with native low trash content. If trashy samples are cleaned to remove trash, processing effect is added. The fiber length variation will be different from the native length distribution. Once again, samples with native low trash content and low processing are expected to provide research results closer to the native length distribution (treatment I).

This research proved the impact of trash on the fiber length distribution analysis. Further research will study the processing effect and clarify the impact of this factor in cotton fiber length quality research.

Acknowledgements The authors want to acknowledge Cotton Incorporated for funding this research (Grant Number 16-217).

Open Access This article is licensed under a Creative Commons Attribution 4.0 International License, which permits use, sharing, adaptation, distribution and reproduction in any medium or format, as long as you give appropriate credit to the original author(s) and the source, provide a link to the Creative Commons licence, and indicate if changes were made. The images or other third party material in this article are included in the article's Creative Commons licence, unless indicated otherwise in a credit line to the material. If material is not included in the article's Creative Commons licence and your intended use is not permitted by statutory regulation or exceeds the permitted use, you will need to obtain permission directly from the copyright holder. To view a copy of this licence, visit http://creativecommons.org/licenses/by/4.0/. 


\section{References}

ASTM (2012) D2812-07 standard test method for non-lint content of cotton. In: Annual book of ASTM standards. ASTM International, West Conshohocken, p 5

ASTM (2013) ASTM standard D7139-09 standard terminology for cotton fibers. In: ASTM. ASTM International, West Conshohocken, p 5

ASTM (2016) ASTM standard D1776/D1776M-16 standard practice for conditioning and testing textiles. ASTM International, West Conshohocken, pp 1-5

Ayele AG, Kelly BR, Hequet EF (2018) Evaluating within-plant variability of cotton fiber length and maturity. Agron J 110:47-55. https://doi.org/10.2134/agronj2017.06.0359

Bel PD, Columbus EP, Bragg CK, Robert KQ (1991) Effects of mechanical cleaning on cotton fibers: part I: ginning. Text Res J 61:83-88. https://doi.org/10.1177/00405175910610 0205

Boman R, Kelley M, Ashbrook C (2010) Systems agronomic and economic evaluation of cotton varieties in the Texas High Plains. Texas A\&M Agrilife Extension, Lubbock

Campbell BT, Dever JK, Hugie KL, Kelly CM (2018) Cotton fiber improvement through breeding and biotechnology. In: Fang D (ed) Cotton fiber: physics, chemistry and biology. Springer, Cham, pp 193-215

Chu Y-T, Riley CR (1997) New interpretation of the fibrogram. Text Res J 67:897-901. https://doi.org/10.1177/0040517 59706701206

Comstock RE, Robinson HF (1948) The components of genetic variance in populations of biparental progenies and their use in estimating the average degree of dominance. In: Biometrics, pp 254-266

Comstock RE, Robinson HF (1952) Estimation of average dominance of genes. In: Gowen JW (ed) Heterosis. Iowa State College Press, Iowa City, pp 494-516

Cotton Incorporated (2013) The classification of cotton, 1st edn. Incorporated Cotton, Cary

Delhom CD, Kelly B, Martin V (2018) Physical properties of cotton fiber and their measurement. In: Fang D (ed) Cotton fiber: physics, chemistry and biology. Springer, Cham, pp 41-73

Elhawary IA (2014) Fiber to yarn: staple-yarn spinning. In: Sinclair R (ed) Textile and fashion-materials, design, and technology. Woodhead Publishing, Sawston, pp 191-211

Ethridge D, Hudson D (1998) Cotton market price information: how it affects the industry. J Cotton Sci 2:68-76

Faulkner WB, Wanjura JD, Hequet EF et al (2011a) Evaluation of modern cotton harvest systems on irrigated cotton: fiber quality. Appl Eng Agric 27:507-513. https://doi.org/10. $13031 / 2013.38197$

Faulkner WB, Wanjura JD, Hequet EF et al (2011b) Evaluation of modern cotton harvest systems on irrigated cotton: harvester performance. Appl Eng Agric 27:497-506. https://doi.org/10.13031/2013.38196

Fristche-Neto R, Akdemir D, Jannink J-L (2018) Accuracy of genomic selection to predict maize single-crosses obtained through different mating designs. Theor Appl Genet 131:1153-1162. https://doi.org/10.1007/s00122-0183068-8
Fryer LF, Rust JP, Lord PR (1996) Effects of cotton fiber blending and processing on HVI measurements-part I. Text Res J 66:349-357. https://doi.org/10.1177/0040517 59606600601

Hertel KL (1940) A method of fibre-length analysis using the fibrograph. Text Res 10:510-520. https://doi.org/10.1177/ 004051754001001203

Hertel KL, Zervigon MG (1936) An optical method for the length analysis of cotton fibres. Text Res 6:331-339. https://doi.org/10.1177/004051753600600707

Hill J, Becker HC, Tigerstedt PMA (1998) Quantitative and ecological aspects of plant breeding, 1st edn. Springer, Dordrecht

Kelley M, Keys K (2015) Systems agronomic and economic evaluation of cotton varieties in the Texas High Plains. Texas A\&M Agrilife Extension, Lubbock

Kelly BR, Hequet EF (2018) Variation in the advanced fiber information system cotton fiber length-by-number distribution captured by high volume instrument fiber length parameters. Text Res J 88:754-765. https://doi.org/10. $1177 / 0040517516688628$

Kelly CM, Hequet EF, Dever JK (2013) Breeding for improved yarn quality: modifying fiber length distribution. Ind Crops Prod 42:386-396. https://doi.org/10.1016/j.indcrop.2012. 06.018

Keskin M, Dodd RB, Han YJ, Khalilian A (2001) Comparison of different types of light sources for optical cotton mass measurement. Trans ASAE 44:715-720

Krifa M (2006) Fiber length distribution in cotton processing: dominant features and interaction effects. Text Res J 76:426-435. https://doi.org/10.1177/0040517506062616

Liu Y, Delhom C (2018) Effect of instrumental leaf grade on HVI micronaire measurement in commercial cotton bales. J Cotton Sci 22:136-141

Lord E (1955) 10-Air flow through plugs of textile fibres part I-general flow relations. J Text Inst Trans 46:T191-T213. https://doi.org/10.1080/19447027.1955.10750307

Lord E (1956) 2-Air flow through plugs of textile fibres: part II. The micronaire test for cotton. J Text Inst Trans 47:T16T47. https://doi.org/10.1080/19447027.1956.10750375

Naylor GR, Delhom CD, Cui X et al (2014) Understanding the influence of fiber length on the high volume instrument ${ }^{\mathrm{TM}}$ measurement of cotton fiber strength. Text Res J 84:979-988. https://doi.org/10.1177/0040517513515318

Peirce FT, Lord E (1939) 13-The fineness and maturity of cotton. J Text Inst Trans 30:T173-T210. https://doi.org/10. 1080/19447023908659334

Pfeiffenberger GW (1944) The Shirley analyzer. Text Res 14:50-54. https://doi.org/10.1177/004051754401400206

Shofner FM (1985) Apparatus and methods for aeromechanical and electrodynamic release and separation of foreign matter from fiber, 15

Shofner FM, Shofner CK (1999) Aeromechanical individualizer, 6

Shofner FM, Baldwin JC, Galyon ME, Chu Y-T (1995) Apparatus and methods for measurement and classification of generalized neplike entities in fiber samples, 37

Snowden C, Ritchie G, Cave J et al (2013) Multiple irrigation levels affect boll distribution, yield, and fiber micronaire in cotton. Agron J. https://doi.org/10.2134/agronj2013.0084 
Stewart JM, Oosterhuis DM, Heitholt JJ, Mauney JR (2010) Physiology of Cotton, 1st edn. Springer, Dordrecht

Tang B, Jenkins JN, Watson CE et al (1996) Evaluation of genetic variances, heritabilities, and correlations for yield and fiber traits among cotton F2 hybrid populations. Euphytica 91:315-322. https://doi.org/10.1007/ BF00033093

van der Sluijs MH, Hunter L (2016) A review on the formation, causes, measurement, implications and reduction of neps during cotton processing. Text Prog 48:221-323. https:// doi.org/10.1080/00405167.2016.1233656

van der Sluijs MHJ, Hunter L (2017) Cotton contamination. Text Prog 49:137-171. https://doi.org/10.1080/00405167. 2018.1437008

Publisher's Note Springer Nature remains neutral with regard to jurisdictional claims in published maps and institutional affiliations. 